\title{
Evaluation of In vitro Antioxidant Properties of Hydro Alcoholic Extract of Entire Plant of Cynodon dactylon
}

\author{
Roopesh Poojary', Nayanatara Arun Kumar', Reshma Kumarachandra², Ganesh Sanjeev ${ }^{3}$ \\ ${ }^{1}$ Department of Physiology, Kasturba Medical College, Bejai, Mangalore, Manipal University, Karnataka, INDIA \\ ²Department of Biochemistry, Kasturba Medical College, Bejai, Mangalore, Manipal University, Karnataka, INDIA. \\ ${ }^{3}$ Department of Studies in Physics, Microton centre, Mangalore University, Mangalagangotri, Karnantaka, INDIA.
}

\begin{abstract}
Background: Antioxidant plays a key role in preventing and scavenging free radicals providing safeguard to humans against diseases. Recent research has been directed towards "Natural antioxidants" from the herbal plants due to safe therapeutic potential. Information pertaining tothe antioxidant properties of entire plant of the Cynodon dactylon is very less. The present study was designed to investigate the antioxidant properties of entire plant of Cynodon dactylon. Method: The powdered crude drugs were extracted with hydro-alcoholic solvent by Soxhlet apparatus. The antioxidant potential along with the phytochemical screening was assessed. Results: Phytochemical screening of the plant showed the presence of flavonoids tannins, steroids, saponins, glycosides and alkaloids. The HPLC analysis showed the presence bioactive polyphenolic flavonoids. The antioxidant nature of the plant was confirmed by its ABTS radical scavenging activity, hydroxyl radical scavenging potential, Nitric oxide free radical scavenging activity and total antioxidant level. Conclusion: The entire plant of Cynodon dactylon is a natural source of antioxidant substances of high importance, which might be effective as a therapeutic agent in the treatment of various diseases.
\end{abstract}

Key words: Cynodon dactylon, Entire plant, Antioxidants, Hydroalcoholic, Flavonoid, ABTS, Hydroxyl radical.

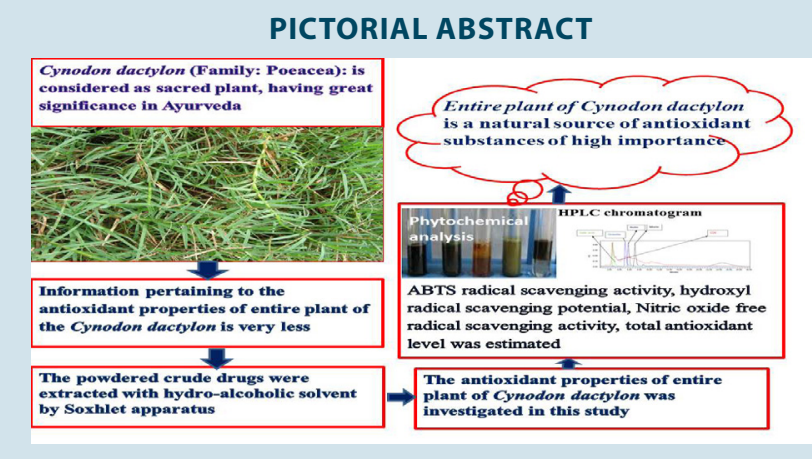

Correspondence :

Dr. Nayanatara Arun Kumar,

Associate Professor in Physiology, Kasturba Medical College (Manipal University)-Bejai, Mangalore- 575004, Karnataka, INDIA. Phone number: $9845551070 ;$ Fax: 918242428183

E-mail: nayanaarun@hotmail.com

DOI: 10.5530/jyp.2016.4.13

\section{INTRODUCTION}

The interaction between free radicals, antioxidants, and co-factors is essential in maintaining health, aging and age-related neurodegenerative diseases. ${ }^{1}$ Free radical induces oxidative stress. Imbalance between oxidants and antioxidants and causes oxidative stress. Hence, for maintaining a good biological system the equilibrium between free radicals and antioxidants is believed to be a critical concept. Even though, our biological systems has an internal defense mechanism to fight against intracellular free radicals at a certain point this fails due to the over expression of free radicals. ${ }^{2}$ Hence, identification of alternate source of antioxidants is required for conferring protection to body cells. Literature survey shows the significant role of reactive oxygen species and other oxidants in causing numerous disorders and diseases. ${ }^{3-5}$ This has gained the attention of scientists to an appreciation of antioxidants helping in the maintenance of human health for prevention and treatment of diseases.

Synthetic antioxidants have been assumed to cause negative health effects. Hence, strong restrictions have been placed on their application and there is a trend to substitute them with antioxidants occurring naturally. In spite of the great advancements observed in modern medicine, plants still make an important contribution to health care. However, in the developing countries more interest in medicinal plants arises from their long use in folk medicines as well as their prophylactic properties. Previous research shows the inverse relation between the mortality from diseases and the consumption of plant products, which could be due to the presence of various antioxidant compounds. ${ }^{6-8}$ Recently there has been an upsurge of interest in the therapeutic potential medicinal plants as antioxidants in reducing oxidative stress. Among the numerous naturally occurring antioxidants; ascorbic acid, carotenoids and phenolic compounds are more effective in inhibiting lipid peroxidation to scavenge free radicals and active oxygen species.

Cynodon dactylon (Family: Poaceae, Aruvampillu in Tamil, Dhub in Hindi, Bermuda grass inEnglish, Garike in Kannada) is a creeping herb rooting at the joints with smooth upward stem. The plant has been used as a folk remedy for various health disorder. ${ }^{9-11}$ Ethanol extract of root stalk of Cynodon dactylon has showed a marked diureticactivity. ${ }^{12}$ Aerial parts have also been marked as a CNS depressant. ${ }^{13}$ However; information pertaining to the antioxidant properties of entire plant of the Cynodon dactylon is very less. The present study was designed to investigate the of in vitro Antioxidant Properties of hydro alcoholic extract of entire plant of Cynodon dactylon by estimating the phytoconstituents, ABTS radical scavenging activity, hydroxyl radical scavenging potential, Nitric oxide free radical scavenging activity and total antioxidant level.

\section{MATERIALS AND METHOD}

\section{Collection of Plant material}

The whole plant along with the roots of Cynodon dactylon was collected from the campus of Kasturba Medical College, Manipal University. The taxonomical identification and authentication was done by Mrs. Usharani S. Suvarna, Department of Botany, Mahatma Gandhi Memorial College Udupi Karnataka. 


\section{Preparation of plant extract}

The collected plant was washed thoroughly in tap water and dried in room temperature for 15 days. The dried plant was powdered. The hydro alcoholic extract was prepared by the extraction of $100 \mathrm{~g}$ of plant powder in $50 \%$ of methanol in water (Total volume of $500 \mathrm{ml}$ ) and refluxed at $50^{\circ} \mathrm{C}$ in a soxhlet apparatus for $72 \mathrm{hrs}$. The liquid extract was cooled and concentrated by evaporation. The extract was kept in sterile bottles, under refrigerated conditions, until further use. They were used directly for the assessment of antioxidant capacity.

\section{Chemicals and Reagents}

Rutin, ABTS [2, 2-azinoibis-(3-ethylbenzothiazoline-6-sulphonate)], 2-Deoxy-D-Ribose, Ascorbic acid were procured through Sigma Aldrich Chemicals and other chemicals and reagents used were of analytical grade.

\section{Preliminary phytochemical testing}

The extract was subjected to preliminary phytochemical testing to detect for the presence of different chemical groups of compounds. Hydroalcoholic extract of the entire plant of Cynodon dactylon was screened for the presence of flavonoids tannins, steroids, saponins, glycosides and alkaloids qualitatively as described in literatures. ${ }^{14}$

\section{Determination of Total Flavonoid Content}

Total flavonoid content was determined using colorimetric method described by Dewanto, $\mathrm{Wu}$, Adom, and $\mathrm{Liu}^{15}$ with slight modification. Briefly, $0.5 \mathrm{ml}$ of the extract was mixed with $1.5 \mathrm{ml}$ of distilled water in a test tube followed by addition of $0.3 \mathrm{ml}$ of $5 \% \mathrm{NaNO}_{2}$ solution. After $5 \mathrm{~min}, 0.3 \mathrm{ml}$ of a $10 \% \mathrm{AlCl}^{3} 6 \mathrm{H}_{2} 0$ solution was added and allowed to stand for another $5 \mathrm{~min}$ before $1.0 \mathrm{ml}$ of $1 \mathrm{M} \mathrm{NaOH}$ was added. The mixture was mixed well with vortex. The absorbance was measured immediately at $510 \mathrm{~nm}$ using spectrophotometer. Results were expressed as $\mathrm{mg}$ rutin equivalents in $1 \mathrm{~g}$ of dried sample ( $\mathrm{mg} \mathrm{RE} / \mathrm{g}$ ).

\section{Determination of Hydroxyl radical scavenging assay}

The influence of plant extracts on Hydroxyl radical was measured by the modified method described by Naskar et al. ${ }^{16}$ Hydroxyl radicals produced by the reduction of by iron in the presence of ascorbic acid degrade deoxyribose to form products which on heating with Thiobarbituric acid form a pink colour chromogen. Aliquots containing various concentration $(2-10 \mu \mathrm{g} / \mathrm{ml})$ of Cynodon dactylon extract in final volume of $1 \mathrm{ml}$ was mixed with $0.1 \mathrm{ml}$ of $(1 \mathrm{mM})$ EDTA, $0.01 \mathrm{ml}$ of Fecl $(10 \mathrm{mM})$, $0.1 \mathrm{ml} \mathrm{H}_{2} \mathrm{O}_{2}(10 \mathrm{mM}), 360 \mu \mathrm{l}$ of 2- Deoxy d-ribose $(10 \mathrm{mM}), 330 \mu \mathrm{l}$ of phosphate buffer saline $\mathrm{pH} 7.4(50 \mathrm{mM}), 0.1 \mathrm{ml}$ of ascorbic acid $(1 \mathrm{mM})$. The reaction mixture was incubated at $37^{\circ} \mathrm{C}$ for one $\mathrm{hr} .1 \mathrm{ml}$ of $0.5 \%$ TBA and $1 \mathrm{ml}$ of $10 \%$ TCA were added to reaction mixture and heated in a boiling water bath for $20-30$ min till the solution turned pink. The absorbance was measured at $532 \mathrm{~nm}$ by UV Vis spectrophotometer 117 (Systronics). Rutin was used as standard for comparison.

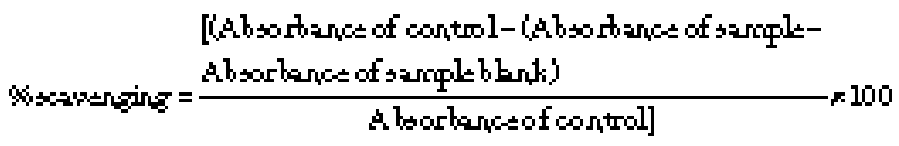

\section{Determination of ABTS Free Radical Scavenging Activity}

ABTS Free radical scavenging activity of hydroalcoholic plant extract was determined by spectrophotometric method. ${ }^{17}$ ABTS free radical cations $\left(\mathrm{ABTS}^{+}\right)$were generated in vitro by treating ammonium per sulphate $(2.45 \mathrm{mM})$ with ABTS $(7 \mathrm{mM})$ solution. The mixture was undisturbed for 12-16 hrs. The mixture was kept in dark at room temperature. $0.5 \mathrm{ml}$ of various concentrations of leaf extract $(2-10 \mu \mathrm{g} / \mathrm{ml})$ was treated with $0.3 \mathrm{ml}$ of ABTS solution and the final volume was made up to $1 \mathrm{ml}$ with distilled water. The absorbance was read at $745 \mathrm{~nm}$ and experiments were done in triplicates. Ascorbic acid was used as standard for comparison. The percentage of ABTS free radical scavenging activity was calculated using the formula.

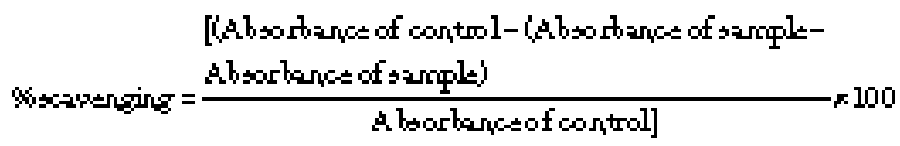

\section{HPLC Quantification of flavonoids in hydro alcoholic extract of Cynodon dactylon with their respective standards}

The flavonoid content in the crude extract of was determined by HPLC method. Alliance 2690 separation module (Dual Lambda Absorbance Detection) made by Waters Pvt Ltd was used. The system is maintained by Empower II software. The analysis was carried out by the column, Luna $5 \mu \mathrm{C}_{18}$ phenmax $\mathrm{C}_{18}$ of diameter $250 \times 4.6$ with $5 \mu \mathrm{m}$ particle size. $10 \mathrm{mg}$ in $1 \mathrm{ml}$ of standard was prepared in methanol $10 \mu \mathrm{l}$ of standard was injected into the column. The set run time was $30 \mathrm{~min}$. The flow rate was $1 \mathrm{ml} / \mathrm{min}$. The flavonoid content was identified depending on the retention time of standards. ${ }^{18}$

\section{Nitric oxide free radical scavenging activity assay}

The procedure ${ }^{19}$ is based on the principle that, sodium nitroprusside in aqueous solution at physiological $\mathrm{pH}$ spontaneously generates nitric oxide which interacts with oxygen to produce nitrite ions that can be estimated using Griess reagent (Sulphanilic acid+Napthalamine). Scavengers of nitric oxide compete with oxygen, leading to reduced production of nitrite ions. For the experiment, sodium nitroprusside (10 mM), in phosphate-buffered saline, was mixed with different concentrations of each extracts dissolved in solvent and incubated at room temperature for $150 \mathrm{~min}$. After the incubation period, Griess reagent was added (When sulphanilic acid is added the nitrites form a diazonium salt. When the azo dye agent (N-Napthalamine) is added pink colour develops. The absorbance of the chromophore formed was read at $546 \mathrm{~nm}$. Rutin was used as standard for comparison. The percentage inhibition by nitric oxide scavenging activity by can be calculated by the following formula.

$\%$ scavenging $=\frac{[\text { Absorbance of sample blank })}{\text { Absorbance of control }]} \times 100$

Procedure: To $0.5 \mathrm{ml}$ of varying concentration of extract and standard (Rutin), $2 \mathrm{ml}$ of $(10 \mathrm{mM})$ sodium nitroprusside, $0.5 \mathrm{ml}$ of phosphate buffer saline (pH-7.4) was added. Incubated at $25^{\circ} \mathrm{C}$ for $150 \mathrm{~min}$. To $0.5 \mathrm{ml}$ of this reaction mixture $1 \mathrm{ml}$ of $(0.33 \%)$ sulfanilic acid was added and allowed to stand at room temperature for $5 \mathrm{~min}$. $1 \mathrm{ml}$ of (1\%) naphthlamine was added and incubated at room temperature for $30 \mathrm{~min}$. Absorbance was read at $540 \mathrm{~nm}$.

\section{Total Antioxidant activity}

Total antioxidant activity of plant extract was determined according to the procedure described by Prieto et al..$^{20}$ The principle is based on the reduction of Mo (VI) to Mo (V) by plant extracts and formation of green phosphate/Mo (V) under acidic ph. $2 \mathrm{ml}$ of various concentration of plant extract was added to $1 \mathrm{ml}$ of total antioxidant reagent (TAC) which comprised of $0.6 \mathrm{M} \mathrm{H}_{2} \mathrm{SO}_{4}, 28 \mathrm{mM}$ sodium phosphate and $4 \mathrm{mM}$ ammonium molybdate. The above solution was incubated at $90^{\circ} \mathrm{C}$ for 
$90 \mathrm{~min}$. The absorbance of reaction mixture was read at $695 \mathrm{~nm}$ using a spectrophotometer.

\section{RESULTS AND DISCUSSION}

\section{Preliminary phytochemical screening}

The preliminary phytochemical investigation showed the presence of various phytochemical constituents such as phenolic acids, flavonoids.

In the present study the results (Table 1) of the qualitative test for flavonoids, tannins, steroids and saponins were positive. Alkaloids and glycosides were absent in the plant extract. Previous research shows that flavonoids group exhibit a wide range of biological activities such as antioxidant, anti-inflammatory, antimicrobial, anti-angionic, anticancer and anti-allergic. ${ }^{21}$ Saponins are other type bioactive chemical constituents which are involved in plant disease resistance because of their antimicrobial activity. ${ }^{22}$ Tannins are phenolic compound and their derivatives are also considered as primary antioxidant or free radical scavengers. ${ }^{23}$ Steroids have been reported to have antibacterial properties, the correlation between membrane lipids and sensitivity for steroidal compound indicates the mechanism in which steroids specifically associate with membrane lipid and exerts its action by causing leakages from liposomes. ${ }^{24}$ The presence of most phytochemicals in Cynodon dactylon might be responsible for their therapeutic potential.

The method developed for HPLC analysis provided a quick analysis of the hydroalcoholic extract. The conditions used led to a good separation of the peaks which could be identified in the chromatogram along with the standard (Figure 1). The retention time obtained for the standards of Gallic acid $\left(\mathrm{R}_{\mathrm{t}}=2.475\right)$, Rutin $\left(\mathrm{R}_{\mathrm{t}}=5.628\right)$ Orientin $\left(\mathrm{R}_{\mathrm{t}}=4.983\right)$ and Morin $\left(R_{t}=6.952\right)$ were compared with the retention time obtained for the plant extract for Gallic acid $\left(\mathrm{R}_{\mathrm{t}}=2.402\right)$, Rutin $\left(\mathrm{R}_{\mathrm{t}}=5.617\right)$ Orientin $\left(\mathrm{R}_{\mathrm{t}}=4.900\right)$ and Morin $\left(\mathrm{R}_{\mathrm{t}}=6.933\right)$. They were identified by comparison with the chromatogram of the four reference compounds obtained under the same conditions and the respective UV spectra, obtained.

Many flavonoids are found to be strong antioxidants effectively scavenging the reactive oxygen species because of their phenolics hydroxyl groups. ${ }^{25}$ Phenolic antioxidants are generally believed to form phenoxyl radical upon donating a hydrogen atom that could quench active free radicals. This has been reported to have multiple biological effects. ${ }^{26}$ Our study showed the presence of four bioactive polyphenolic flavonoids like Gallic acid, Orientin, Rutin, and Morin which might play an important role in improving of oxidative stress.

Flavonoids are plant secondary metabolites widely distributed in the plant kingdom. More than 6000 flavonoids have been identified in plants. ${ }^{26}$ Flavonoids are naturally occurring in plants and are thought to have positive effects on human health. ${ }^{27}$ The hydro alcoholic extracts of Cynodon dactylon was analyzed for their total Flavonoid content and it was observed that whole plant extract of Cynodon dactylon displayed flavonoid content ranging from $1.5 \mathrm{mg} \mathrm{RE} / \mathrm{g}$ to $140 \mathrm{mg} \mathrm{RE} / \mathrm{g}$ of extract (Figure 2). Presence of phenolic and flavonoid compounds might be attributed to the antioxidant activity. Studies on flavonoidic derivatives have shown a wide range of antibacterial, antiviral, anti-inflammatory, anticancer, and anti-allergic activities. ${ }^{27}$

ABTS assay is an excellent tool for determining the antioxidant activity of hydrogen-donating antioxidants and of chain-breaking antioxidants. ${ }^{28}$ In the present study plant extract of Cynodon dactylon, extracts scavenged ABTS free radicals in dose dependent manner. Rutin was used as standard. Percentage inhibition of plant extract at the minimum concentration of $0.2 \mathrm{mg}$ and maximum concentration of $1 \mu \mathrm{g}$ was found to be $36.9 \%$ and $80.2 \%$ respectively, where standard rutin showed the saturation of $71.8 \%$ and $93.8 \%$ respectively (Figure 3 ). Therefore, the ABTS radical scavenging activity of entire plant of Cynodon dactylon indicates its ability to scavenge free radicals.

Hydrogen peroxide is a neutral molecule formed during the dismutation of superoxide by superoxide dismutase which freely diffuses out of the lipid bilayer, thereby targeting other biomolecules, namely proteins, lipids, etc. which comes in contact. However, it may be toxic if converted to hydroxyl radical in the cell. Scavenging of hydrogen peroxide by the plant extracts may be attributed to their phenolics, which donate electron to hydrogen peroxide, thus reducing it to water ${ }^{29}$ At $100 \mu \mathrm{g}$ concentration plant extract displayed $51.8 \pm 0.96 \%$ hydroxyl radical scavenging activity respectively, as compared to standard Rutin which displayed $85.24 \pm 0.22 \%$ scavenging activity (Figure 4 ). In the present study the plant extract was capable of scavenging hydrogen peroxide in a dose dependent manner.

The role of nitric oxide (NO) in numerous diseases has generated a considerable discussion over the past several years. NO is apotent bio regulatory molecule possessing various physiological effects including control of blood pressure, neural signal transduction, platelet function, antimicrobial and antitumor activity. ${ }^{30}$ However, excess production of NO is associated with several diseases. $\mathrm{NO}$ and its derivatives produced by the activated phagocytes might have genotoxic effect contributing in the multistage carcinogenesis process. ${ }^{31,32}$ It would be interesting to develop potent and selective inhibitors of NO for potential therapeutic use In our study the scavenging activity of plant extract at the minimum concentration of $20 \mu \mathrm{g}$ and maximum concentration of $100 \mu \mathrm{g}$ was found to be $7.01 \%$ and $41.8 \%$. Whereas, standard Rutin was $45.8 \%$ and $74.3 \%$ respectively (Figure 5). The present results shows that entire plant of Cynodon dactylon might have the property to counteract the effect of $\mathrm{NO}$ formation which might be helpful in preventing the ill effects of excessive NO generation in vivo.

The phosphomolybdenum assay evaluates both water-soluble and fatsoluble antioxidant capacity. ${ }^{20}$ Electron transfer occurs in this assay depends on the structure of the antioxidant. In our study the hydro alcoholic plant extract of Cynodon dactylon contains 11.52 to $220 \mathrm{mg}$ of Rutin equivalence per gram of extract at concentration of 20 to $100 \mu \mathrm{g} / \mathrm{ml}$. This shows that Cynodon dactylon exhibited total antioxidant activity in a dose dependent manner (Figure 6). The extracts might have acted as radical chain terminators, transforming reactive free radical species into more stable non-reactive products. The antioxidant property of this plant might be due to the presence of phenolic compounds. Phenolic

Table 1: Phytochemicals screening analysis of entire plant of Cynodon dactylon extract $(+=$ present, $-=$ absent)

\begin{tabular}{cc}
\hline Test & CDE (Cynodon dactylon extract) \\
\hline Flavonoids & + \\
Tannins & + \\
Steroids & + \\
Saponins & + \\
Alkaloid & - \\
Glycosides & + \\
\hline
\end{tabular}




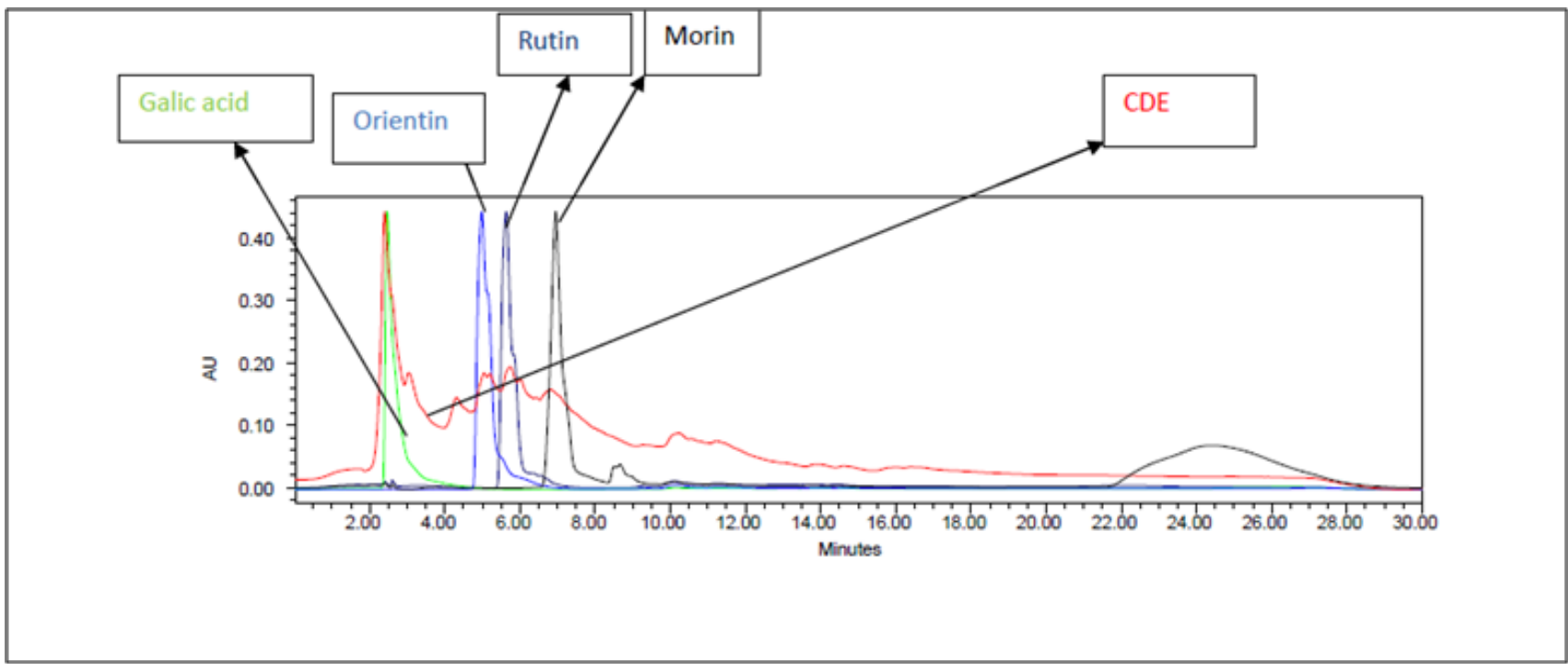

Figure 1: Chromatogram showing the presence of flavonoids in the entire plant of Cynodon dactylon extract along with reference standards.

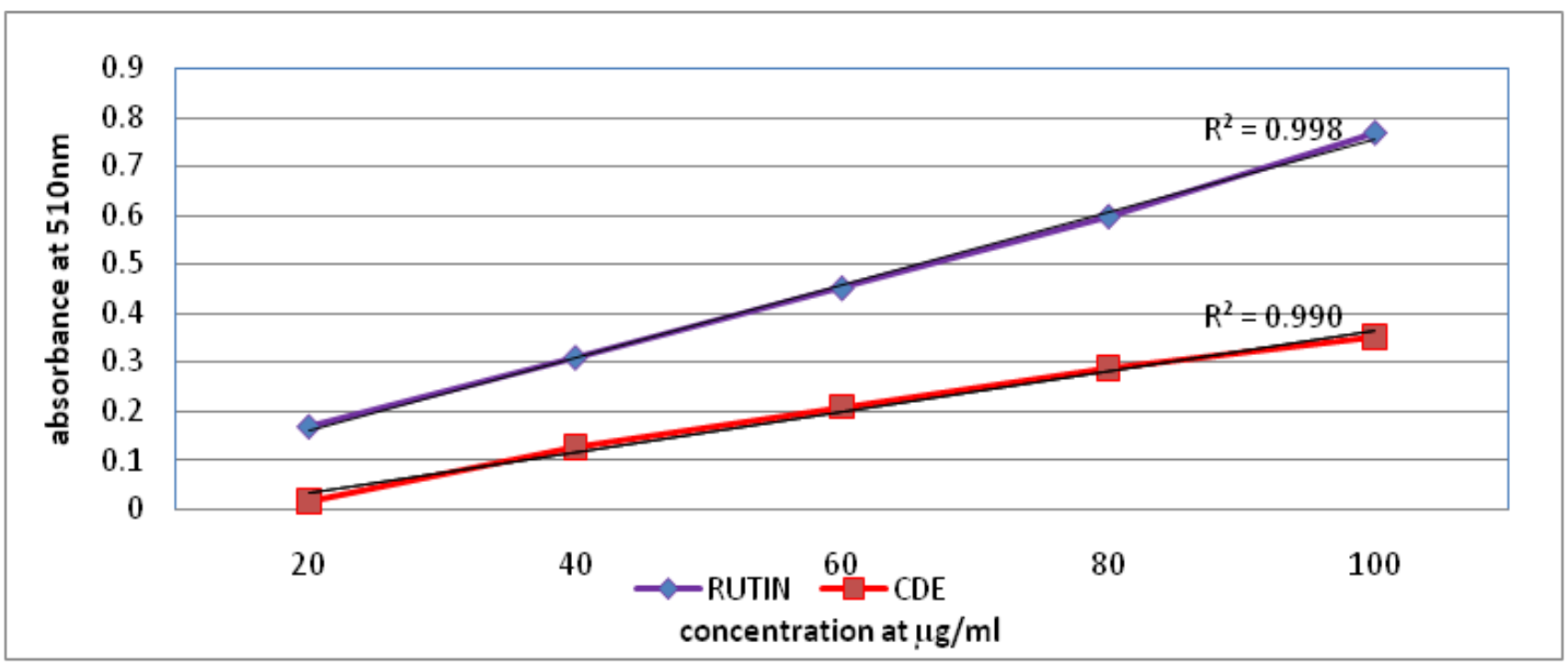

Figure 2: Estimation oftotal flavonoid content of hydroalcoholic extract of entire plant of Cynodon dactylon.

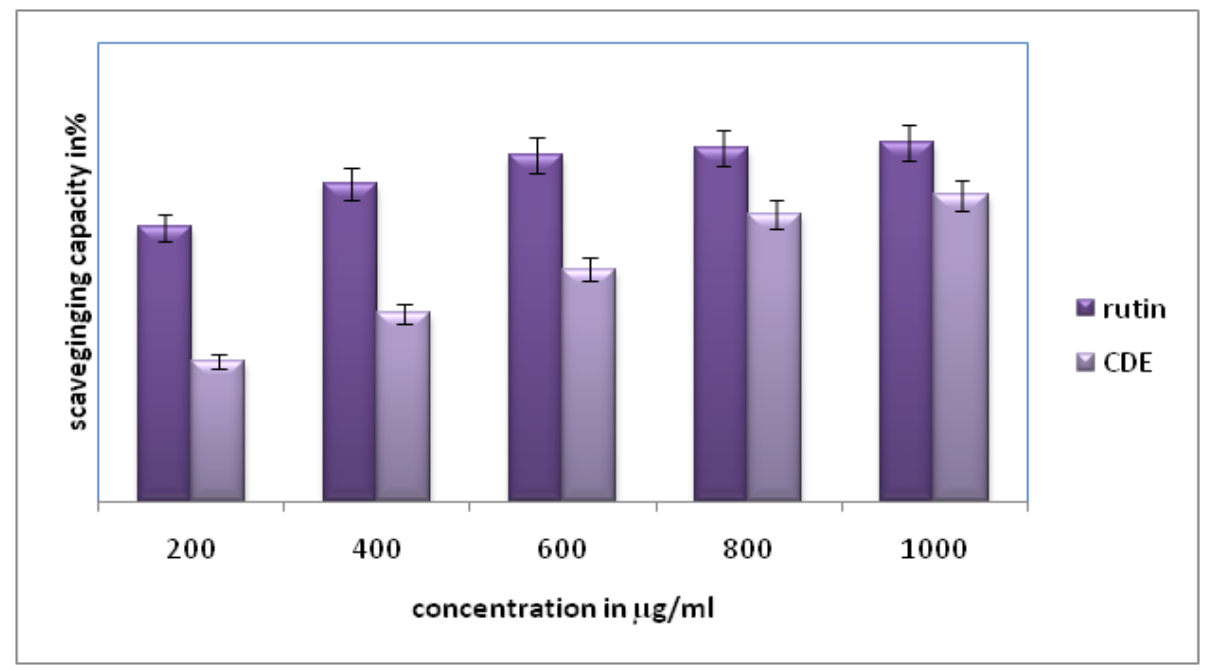

Figure 3: Estimation of ABTS scavenging assayof hydroalcoholic extract of entire plant of Cynodon dactylon. 


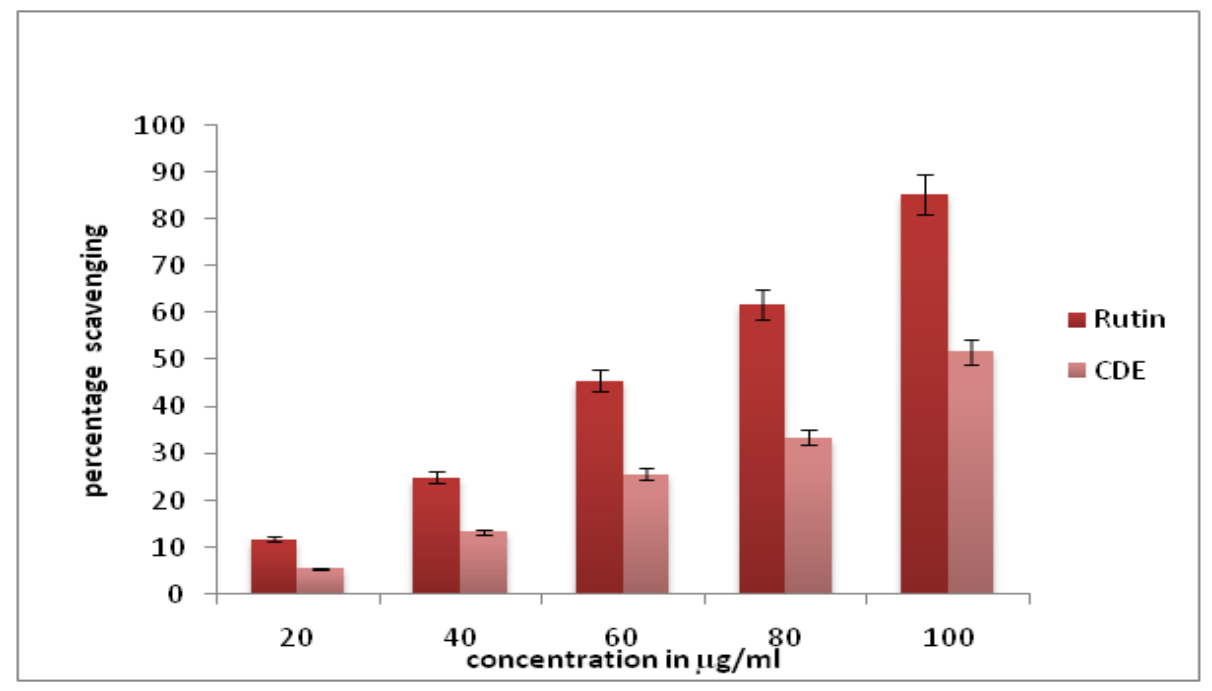

Figure 4: Estimation of Hydroxyl radical scavenging activity of entire plant of Cynodon dactylon.

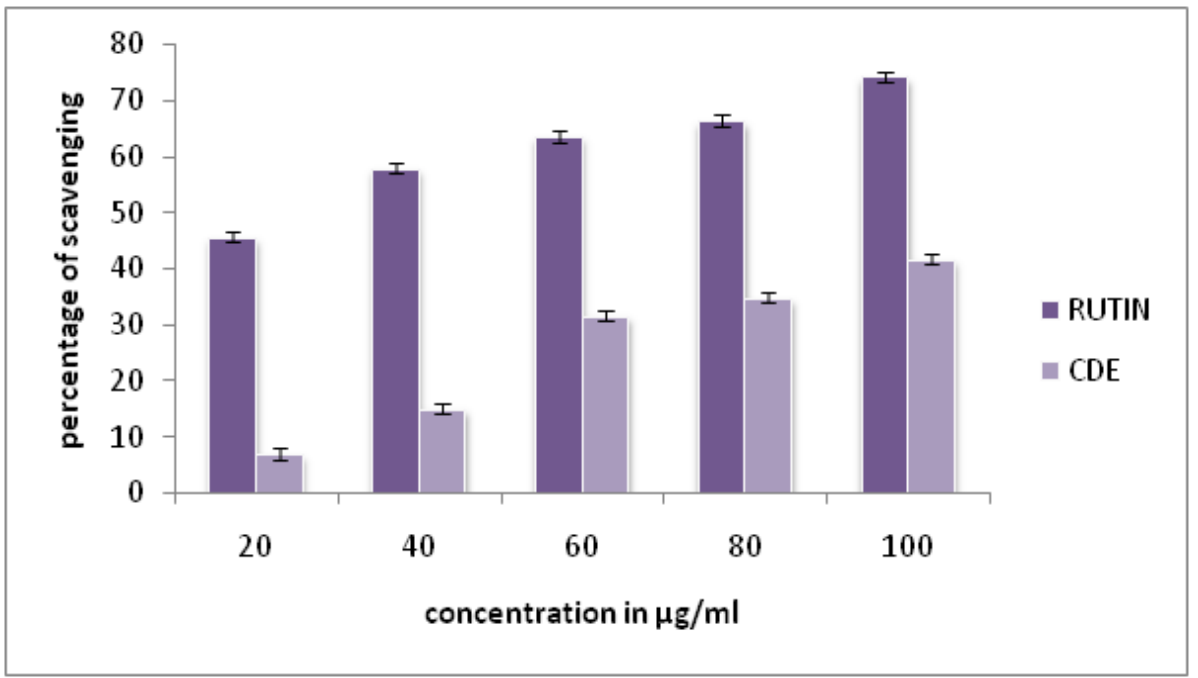

Figure 5: Estimation of Nitric oxide free radical scavenging activity assay of the entire plant of Cynodon dactylon.

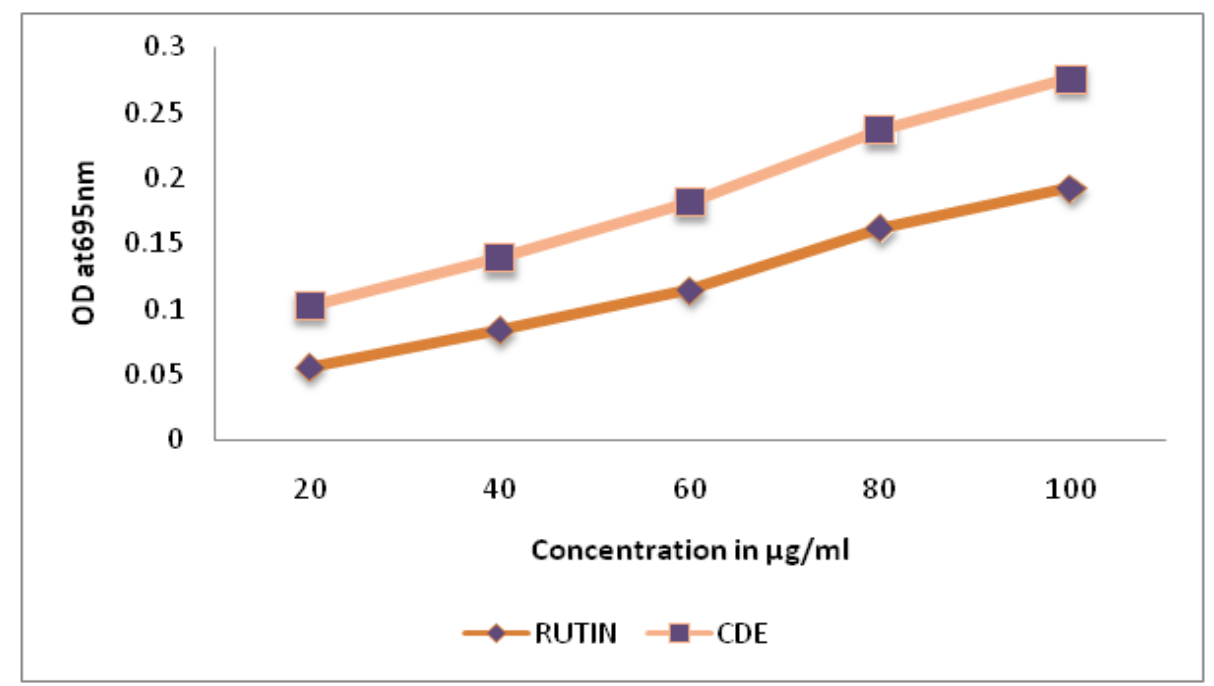

Figure 6: Evaluation of the total Antioxidant activity of the entire plant of Cynodon dactylon. 
compounds due to their redox properties can play animportant role in absorbing and neutralizing free radicals, quenching singlet and triplet oxygen, or decomposingperoxides. ${ }^{33}$

\section{CONCLUSION}

Results of our study suggest the great value of entire plant of Cynodon dactylon possessing significant antioxidant activityby its ABTS radical scavenging activity, hydroxyl radical scavenging potential and the presence of the potent bioactive polyphenols. The preliminary phytochemical screening of the plant indicated the presence of flavonoids tannins, steroids, saponins, glycosides and alkaloids. Based on this information, it could be concluded that this plant is a natural sources of antioxidant substances of high importance. Further studies of this plant species should be directed to carry out in vivo studies of its medicinal active components in order to prepare natural pharmaceutical products of high value. Our results might be helpful for providing the platform for researchers and pharma companies for the development of precious medicines which will be helpful for treatment of various diseases.

\section{ACKNOWLEDGEMENT}

The authors are very grateful to Board of Research in Nuclear science (BRNS), Department of Atomic Energy, Bombay, Government of India for the financial support provided for this project (Sanction No.34 (1)/14/38/2014-BRNS).

\section{CONFLICT OF INTEREST}

The authors declare no conflict of interest.

\section{ABBREVIATION USED}

HPLC: High Performance Liquid Chromatography; ABTS: 2,2 Azino-bis3-ethylbenzothiazoline-6-sulphonicacid; CNS: Central Nervous System; RE: Rutin Equivalent; EDTA: Ethylenediaminetetraacetic acid (EDTA); TBA: Thiobarbutiric acid; TCA: Tri-chloro acetic acid; UV: Ultra violet; TAC: Total antioxidant reagent; RT: Retention time; NO: Nitric Oxide; CDE: Cynodon dactylon Extract; OD: Optical Density.

\section{ABOUT AUTHORS}

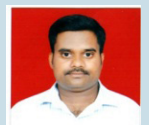

Mr. Roopesh Poojary: Is a Research Scholar in Kasturba Medical College Mangalore, Manipal University, Karnataka, India. He has completed M.Sc. in the subject of Biotechnology at St. Aloysius College Mangalore, affiliated to Mangalore University, he is working as a Junior Research Fellow on the project funded by Board of Research in Nuclear Science Department of Atomic Energy, Government of India in the area of Radiation biology, he has two publications and presented his work in National Conferences.

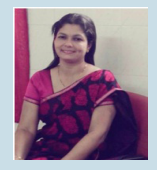

Dr. Nayanatara Arun Kumar: Is currently working as anAssociate Professor of Physiology, Kasturba Medical College Mangalore, Manipal University. She is a recognized Ph.D guide of Manipal University. Her research area is mainly focused on stress, Radioprotective effects of herbal extracts, neurophysiology, stress, food additives and alcohol. She has more than 75 research publications in International and National indexed journals. She has made her research paper presentations in various National and International conferences in India and overseas. She has been working as a Principal Investigator for BRNS funded project and has been appointed as a reviewer for various National and International reputed journals.

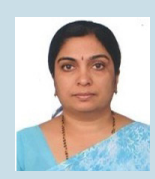

Dr. Reshma Kumarachandra: Is currently working as an Associate Professor in the Department of Biochemistry, Kasturba Medical College Mangalore (Manipal University). She is a recognized Ph.D guide of Manipal University. She has received the TMA Pai Gold Medal for best Research paper in KMC, Mangalore, Manipal university Her research area is mainly focused on Radioprotective effects of herbal extracts, medicinal plants and also their role in cancer prevention /treatment. She has more than 26 Research Publications. She has made research paper presentations in various National and International conferences in India and overseas. She has been working as a Principal Investigator/Coinvestigator for BRNS funded projects.

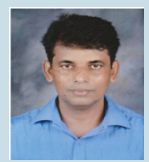

Dr. Ganesh Sanjev: Professor of Physics and Head, Microtron Centre, Mangalore University has been working in the areas of Radiation Dosimetry, Photofission, Radiation Processing of materials and devices, Biophysics and microtron based research activities since last two decades. He has 197 publications to his credit in refeeed journals and 173 presentations / publications in national and international conferences / seminars. He has worked in most of the BRNS sanctioned 119 Microtron based research projects as Principal Investigator / Principal Collaboarator / Coinvestigator.

\section{REFERENCES}

1. Agarwal S, Sohal R. Relationship between susceptibility to protein oxidation, aging, and maximum life span potential of different species. Exp Gerontol. 1996;31(3):365-72

2. Halliwell B, Gutteridge J. Free radicals in biology and medicine. Oxford: Clarendon Press; 1985.

3. Pramod J, Singh S, Singh J. Role of Free Radicals And Antioxidants In Human Health And Disease. IJCRR. 2013;5(19):14-22.

4. Shinde A, Ganu J, Naik P. Effect of Free Radicals and Antioxidants on Oxidative Stress: A Review. J Dent Allied Sci. 2012;1(2):63.

5. Kunwar A, Priyadarsini K. Free radicals, oxidative stress and importance of antioxidants in human health. J Med Allied Sci. 2011;1(2):53-60.

6. Scalbert A, Manach C, Morand C, Rémésy C, Jiménez L. Dietary Polyphenols and the Prevention of Diseases. Crit Rev Food Sci Nutr. 2005;45(4):287-306.
7. Spencer J, Abd El Mohsen M, Minihane A, Mathers J. Biomarkers of the intake of dietary polyphenols: strengths, limitations and application in nutrition research. BJN. 2007;99(01):12-22

8. Beckman C. Phenolic-storing cells: keys to programmed cell death and periderm formation in wilt disease resistance and in general defense responses in plants?. Physiol Mol Plant Pathol. 2000;57(3):101-10.

9. Nayanatara AK, Akshatha A, Kottari S, Soofi AA, Rejeesh EP, Bhagyalakshmi K. Effect of Cynodon dactylon extract on estrous cycle and reproductive organs in female wistar rats. Int J Anal Pharm Biomed Sci. 2015;1(3):10-5.

10. Kaup S, Arunkumar N, Bernhardt L, Vasavi R, Shetty S, Pai S. Antihyperlipedemic activity of Cynodon dactylon extract in high-cholesterol diet fed Wistar rats. Genomic Med Biomarkers Health Sci. 2011;3(3-4):98-102.

11. Nayanatara AK, Kottari S, Alva A, Soofi AA, Rejeesh EP, Bhagyalakshmi $K$ 
Effect of Aqueous Extract of Cynodon dactylon on Reproductive Hormones and Reproductive Organ weight of Female Wistar Rats. Inte J Biology Pharm Allied Sci. 2012;1 (8):1065-76

12. Shivalinge GKP, Satish S, Mahesh CM, Vijay kumar. Study on the Diuretic Activity of Cynodon dactylon root stalk Extract in Albino Rats. Res J Pharm Tech. 2009;2(2):338-40.

13. Pal DK. Evaluation of CNS activities of aerial parts of Cynodon dactylon Pers. in mice. Acta Pol Pharm Drug Res. 2008;65(1):37-43.

14. Sofowora A. Research on medicinal plants and traditional medicine in Africa. J Altern Complement Med. 1996;2(3):365-72.

15. Dewanto V, Wu X, Adom K, Liu R. Thermal Processing Enhances the Nutritional Value of Tomatoes by Increasing Total Antioxidant Activity. J Agric Food Chem. 2002;50(10):3010-4

16. Naskar S, Islam A, Mazumder UK, Saha P, Haldar PK, Gupta M. In vitro and in vivo antioxidant potential of Hydromethanolic extracts of phoenix dactyllifera fruits. J Sci Res. 2010;2(1):144-57.

17. Shirwaikar A, Rajendran K, Kumar CD. In vitro antioxidant studies of Annona squamosa Linn. Leaves. Ind J Exp Biol. 2004;42(8):803-7.

18. Khan R, Khan M, Sahreen S, Ahmed M. Assessment of flavonoids contents and in vitro antioxidant activity of Launaea procumbens. Chemistry Central Journal. 2012;6(1):43:1-11.

19. Garratt D. The quantitative analysis of drugs. London: Chapman and Hall; 1955

20. Prieto P, Pineda M, Anguilar M. Spectrophotometric quantitation of antioxidant capacity through the formation of a Phosphomolybdenum Complex. Specific application to the determination of Vitamin E. Anal Biochem. 1999;269(2):33741.

21. Mohammad A, Elham K. Medicinal uses and chemistry of flavonoid contents of some common edible tropical plants. J Paramed Sci. 2013;4(3):119-38.

22. Anyasor GN, Ogunwenmo O, Oyelana OA, Akpofunure BE. Phytochemical constituents and antioxidant activities of aqueous and methanol stem extracts of Costusafer Ker Gawl. (Costaceae). Afr J Biotechnol. 2010;
9(31):4880-4

23. Chao PDL, Hsiu SL, Hou YC. Flavonoids in herbs: Biological fates and potential interactions with xenobiotics. J Food Drug Anal. 2002;10(4):219-28.

24. Epand R, Savage P, Epand R. Bacterial lipid composition and the antimicrobial efficacy of cationic steroid compounds (Ceragenins). Biochimica et Biophysica Acta (BBA)-Biomembranes. 2007;1768(10):2500-9.

25. Balasundram N, Sundram K, Samman S. Phenolic compounds in plants and agri-industrial by-products: Antioxidant activity, occurrence, and potential uses. Food Chem. 2006;99(1):191-203.

26. Cao G, Sofic E, Prior RL. Antioxidant and pro-oxidant behavior of flavonoids: Structure activity relationships. Free Rad Biol Med. 2009;22:749-60.

27. Oteiza P, Erlejman A, Verstraeten S, Keen C, Fraga C. Flavonoid-membrane Interactions: A Protective Role of Flavonoids at the Membrane Surface?. Clin Developl Immunol. 2005;12(1):19-25.

28. Leong L, Shui G. An investigation of antioxidant capacity of fruits in Singapore markets. Food Chem. 2002;76(1):69-75.

29. Chang HY, Ho YL, Sheu MJ, Lin YH, Tseng MC, Wu SH, et al. Antioxidant and free radical scavenging activities of Phellinus merrillii extracts. Bot Stud. 2007;48(4):407-17

30. Gutteridge J. Reactivity of hydroxyl and hydroxyl-like radicals discriminated by release of thiobarbituric acid-reactive material from deoxy sugars, nucleosides and benzoate. Biochem J. 1984;224(3):761-7.

31. Jagetia G, Rao S, Baliga M, Babu SK. The evaluation of nitric oxide scavenging activity of certain herbal formulations in vitro: a preliminary study. Phytother Res. 2004;18(7):561-5.

32. Liu R, Hotchkiss J. Potential genotoxicity of chronically elevated nitric oxide: A review. Mutation Res/Rev Genetic Toxicol. 1995;339(2):73-89.

33. Roopesh P, Nayanatara AK, Reshma K, Ganesh S. In vitro Assessment of Total Phenolic Content, Iron Chelating, Reducing Potential and DPPH Scavenging Activity of Cynodon dactylon Hydroalcoholic Extract. Int J Pharm Sci Rev Res. 2016;37(1):163-6. 